(2) Open Access Full Text Article

ORIGINALRESEARCH

\title{
Gender Differences in Inhaled Pharmacotherapy Utilization in Patients with Obstructive Airway Diseases (OADs): A Population-Based Study
}

This article was published in the following Dove Press journal: International Journal of Chronic Obstructive Pulmonary Disease

Joseph Emil Amegadzie $\mathbb{D}^{\prime}$ John-Michael Gamble (D) ${ }^{2}$ Jamie Farrell (1D' Zhiwei Gao (D)

'Faculty of Medicine, Memorial University of Newfoundland, Newfoundland, Canada; ${ }^{2}$ Faculty of Science, School of Pharmacy, University of Waterloo, Waterloo, Ontario, Canada
Correspondence: Zhiwei Gao

Faculty of Medicine, Memorial University of Newfoundland, St. John's,

Newfoundland, Canada

Tel + I 7098646523

Email zhiwei.gao@med.mun.ca
Purpose: Gender differences in the incidence, susceptibility and severity of many obstructive airway diseases (OADs) have been well recognized. However, gender differences in the inhaled pharmacotherapy profile are not well characterized.

Methods: We conducted a retrospective cohort study to investigate gender differences in new-users of inhaled corticosteroids (ICS), short-or long-acting beta ${ }_{2}$-agonist (SABA or LABA), ICS/LABA, short-or long-acting muscarinic antagonist (SAMA or LAMA) among patients with asthma, COPD or asthma-COPD overlap (ACO). We used Clinical Practice Research Datalink to identify OAD patients, 18 years and older, who were new-users (1-year washout period) from 01-January-1998 to 31-July-2018. Multivariable logistic regression was used to examine gender differences in each of the inhaled pharmacotherapies after controlling for potential confounders.

Results: A total of 242,079 new-users (asthma: 84.93\%; COPD: $10.19 \%$; ACO: $4.88 \%$ ) of inhaled pharmacotherapies were identified. The multivariable analyses showed that males with COPD were more likely to be a new user of a LABA (odds ratio [OR] 1.29; 95\% confidence interval [CI], 1.12-1.49), LAMA (OR 1.21; 95\% CI 1.10-1.33), SAMA (OR $1.11 ; 95 \%$ CI 1.01-1.21) and less likely to be a new user of a SABA (OR 0.84; 95\% CI, 0.80-0.89) compared to females. Similar patterns were also observed for patients with ACO; males were more likely to be prescribed with LABA (OR 1.26; 95\% CI 1.03-1.55), LAMA (OR 1.28; 95\% CI 1.11-1.48), SAMA (OR 1.28; 95\% CI 1.11-1.48), and less likely to be a new user of a SABA (OR 0.89; 95\% CI, 0.82-0.96). Also, males with asthma were more likely to be a new-user of ICS/LABA (OR 1.15; 95\% CI, 1.08-1.23) and less likely to start an ICS (OR 0.97; 95\% CI, 0.95-0.99) in comparison with females.

Conclusion: Our study showed significant gender differences in new-users of inhaled pharmacotherapies among OAD patients. Adjusting for proxies of disease severity, calendar year, smoking and socioeconomic status did not change the association by gender. Keywords: inhaled pharmacotherapies, asthma, COPD, asthma-COPD overlap, gender, drug utilization

\section{Introduction}

Asthma and chronic obstructive pulmonary disease (COPD) are the two most common categories of respiratory diseases characterized by airway obstruction. ${ }^{1,2}$ Recently a new phenotype, referred to as asthma-COPD overlap (ACO), has been identified with its first guidelines for treatment and management in effect since $2015 .^{3}$ Gender differences exist in most common health conditions and especially in 
lung diseases such as asthma and COPD. ${ }^{4}$ These assertions have been evident by many studies showing significant differences in medical treatments between females and males with the same respiratory condition such as asthma and COPD. ${ }^{5-7}$ Although the mechanisms of gender differences are not fully understood, many population studies and cluster analyses have shown that gender, race, environment, genetics and specific phenotypes have played important roles in asthma symptoms and management. ${ }^{8-10}$

The airflow obstruction in patients with obstructive airway diseases (OADs) is either fixed or reversible by medication. ${ }^{11}$ The clinical guidelines for asthma, COPD and asthma-COPD overlap convey equal treatment between males and females. ${ }^{1}$ For patients with asthma, the Global Initiative for Asthma (GINA) guideline recommends treating everyone with combination therapy of inhaled corticosteroid/long-acting beta 2 -agonist (ICS/ LABA) on an as-needed basis, even for mild patients (GINA step 1 and step 2). ${ }^{1}$

The clinical guideline for COPD proposes building up treatment from short-acting beta ${ }_{2}$-agonist (SABA) to single LABA or long-acting muscarinic antagonist (LAMA) to combination therapy of LABA/LAMA, then step-up to ICS/LABA/LAMA triple therapy in those with frequent acute exacerbation chronic obstructive pulmonary disease (AECOPD) or persistent symptoms; whist the asthmaCOPD overlap guideline advocates treatment with asthma medication and to continue steadily with COPD medications as the disease progresses to lessen the risk of exacerbations. ${ }^{2}$ Furtherance to this suggestion, a recent systematic review concluded that patients with asthmaCOPD overlap may benefit from combination therapy of inhaled corticosteroids/long-acting beta ${ }_{2}$-agonist (ICS/ LABA) combination therapy which appears to reduce the risk of death or hospitalization. ${ }^{12}$

Over the years, gender-specific epidemiological studies and clinical trials have been lacking in detailing differences in pharmacotherapy utilization in patients with obstructive airways diseases which may have important implications in symptoms and disease management. ${ }^{13,14}$ However, this phenomenon has long been established in cardiovascular disease and is labelled as Yentl syndrome stating female receive generally less treatment (across the spectrum of medical and interventional therapy) for ischaemic heart disease than their male equivalents. ${ }^{15,16}$

Whilst it is evident that recommendations for treatment with inhaled pharmacotherapy for asthma, COPD and asthma-COPD overlap have changed tremendously over several decades, gender differences in inhaled pharmacotherapy of asthma, COPD and asthma-COPD overlap in both randomized control trials and observational studies have not been demonstrated before. Therefore, we sought to investigate gender differences in new-users of ICS monotherapy, ICS/LABA combination therapy, LABA monotherapy, LAMA monotherapy, SABA monotherapy and short-acting muscarinic antagonist (SAMA) monotherapy in patients with asthma, COPD or asthma-COPD overlap.

\section{Methods}

\section{Data Sources}

We conducted a retrospective observational cohort study using primary care records from CPRD. The CPRD is a United Kingdom (UK) based database which is representative of UK population that contains de-identified, longitudinal data, with approximately 700 total contributing general practitioner (GP) primary care practices and more than 14 million acceptable (good quality) patients. ${ }^{17}$ Patients' data are available for demographics, symptoms and diagnoses, primary care prescriptions, test results, referrals to specialist and lifestyle information (smoking, alcohol). Approximately half of the source population (study population) is linked to hospital records (Hospital Episode Stats, HES) and death certificate (Office of National Statistics, ONS) ${ }^{18}$ Our study was conducted in compliance with the ethical principles of the Declaration of Helsinki, International Council for Harmonisation Good Clinical Practice (GCP) and received approval from the Health Research Ethics Board at Memorial University. The study protocol was approved by the CPRD Independent Scientific Advisory Committee (ISAC 18_005RA). Generic ethical approval for observational research using the CPRD with approval from ISAC has been granted by a Health Research Authority (HRA) Research Ethics Committee. Patient informed consent was not necessary since the data were anonymized for research purposes.

\section{Study Population and Identification of Inhaled Pharmacotherapies}

The study population included patients who were registered with up-to-standard practice and active between January 1, 1998 and July 31, 2018 inclusive (Figure 1). This population comprised male and female patients in CPRD database with an incident read code (see supplementary file) for asthma and/or COPD defined as at least one diagnostic record for either 


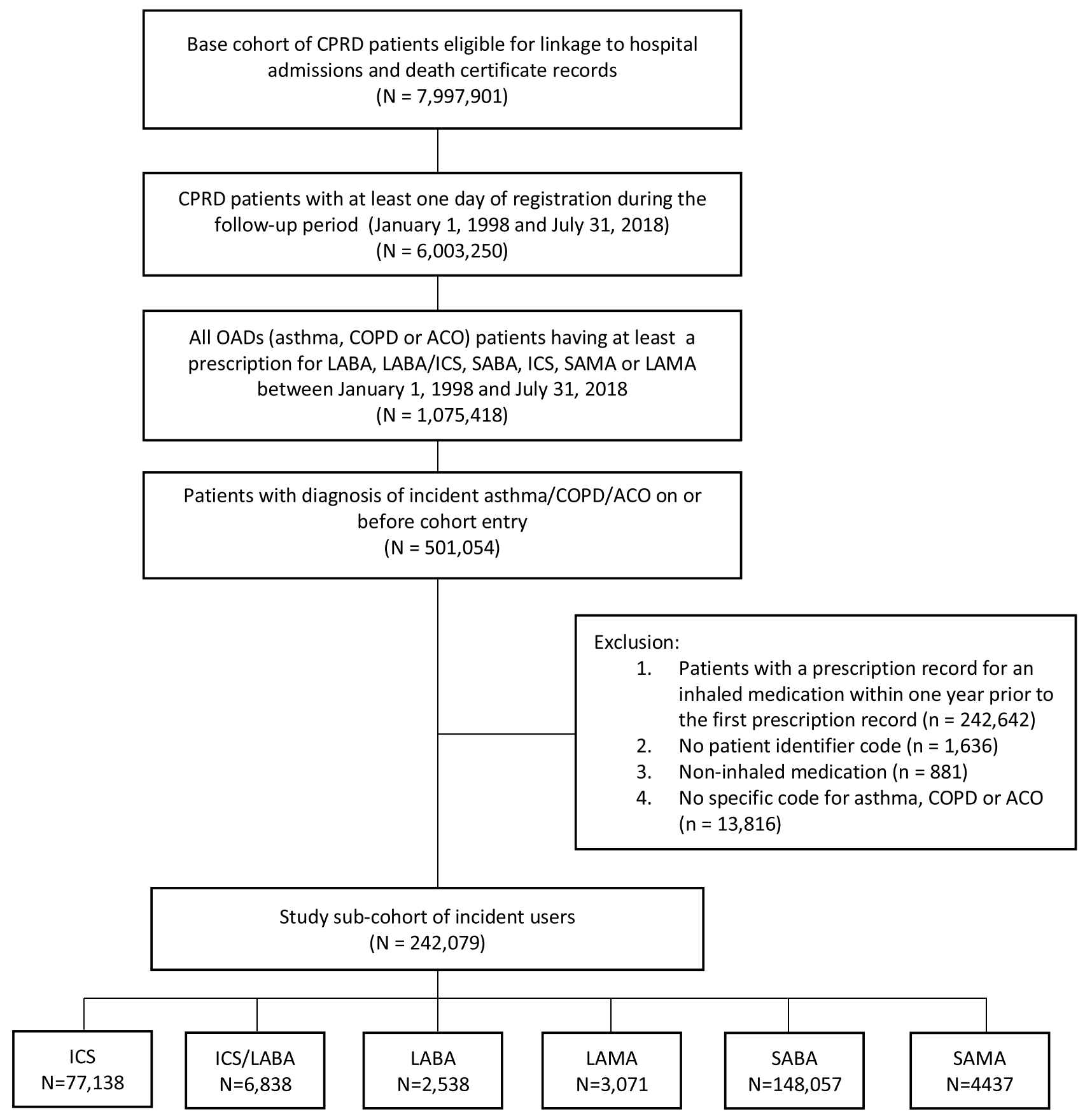

Figure I Flowchart of study cohort formation.

Abbreviations: CPRD, Clinical Practice Research Datalink; OADs, obstructive airway diseases; COPD, chronic obstructive pulmonary disease; ACO, asthma-COPD overlap; ICS, inhaled corticosteroid; LABA, long-acting beta agonist; LAMA, long-acting muscarinic antagonist; SABA, short-acting beta agonist; SAMA, short-acting muscarinic antagonist; Rx, prescription.

disease and a new-user of ICS, SABA, LABA, combination therapy of ICS/LABA, SAMA or LAMA (see supplementary file). Patients with asthma-COPD overlap were defined as having; 1) COPD read code and 2) asthma read code and 3) an ex or current smoker (if never smoked, exposure to wood smoke, biofuels, randon gas or second-hand smoke) before the index date (the date of first prescription of inhaled pharmacotherapy). To identify new-users of inhaled pharmacotherapy, patients with a record of taking any inhaler drug within 365 days before their first medication prescription were excluded. Recent validation studies in the CPRD GOLD database have shown that patients with asthma or COPD can be accurately identified from CPRD database using specific diagnostic codes. $^{19,20}$ 


\section{Exposure and Outcomes}

The primary exposure variable of interest was gender which was defined as either male or female based on medical records from the patient's general practitioner. The outcomes of interests were new-users of the following mutually exclusive categories of inhaled pharmacotherapies:

1. ICS monotherapy (budesonide, fluticasone, mometasone, beclomethasone, ciclesonide and flunisolide);

2. ICS/LABA combination therapy (fluticasone propionate/formoterol fumarate, Budesonide/formoterol fumarate, beclomethasone dipropionate/formoterol fumarate, fluticasone furoate/vilanterol, fluticasone propionate/salmeterol xinafoate, budesonide/formoterol fumarate and mometasone furoate/formoterol fumarate);

3. LABA monotherapy (salmeterol xinafoate, indacaterol maleate, olodaterol, vilanterol and formoterol fumarate);

4. LAMA monotherapy (tiotropium bromide, aclidinium bromide and umeclidinium bromide);

5. SABA monotherapy (salbutamol, terbutaline sulfate, fenoterol hydrobromide, rimiterol, pirbuterol, reproterol and orciprenaline sulfate); or

6. SAMA monotherapy (ipratropium bromide and oxitropium bromide).

New-users were defined using a 1-year washout period whereby no prescription for any agent in the aforementioned categories was recorded in the previous 365 days. We considered only the first treatment; therefore, any subsequent switches, discontinuations or new therapies were not examined in our analysis. Since recommendations on inhaled pharmacotherapy for patients with obstructive lung diseases may have changed over the years, we also considered calendar year in our analysis; 1. First decade spanning January 1, 1998 to December 31, 2007 and 2. Second decade spanning January 1, 2008 to July 31, 2018.

\section{Statistical Analysis}

Descriptive statistics for asthma, COPD and asthmaCOPD overlap including count/percentage and mean/standard deviation were provided for categorical and continuous variables, respectively. For categorical variables with more than two categories, type $3 p$-values (a $p$-value indicating the overall effect of all levels of a categorical variable) were also calculated. An interaction term between gender and a variable indicating OAD types (asthma, COPD or asthma-COPD overlap) was introduced into multivariable models to examine the association between gender and a pharmacotherapy for patients with asthma, COPD and asthma-COPD overlap, respectively. The initial multivariable model included clinical important variables and all variables which were significant at $p=0.20$ in the univariate analysis. Then we started by removing the least significant variable one at a time, until all the variables in the final multivariable model are either clinically important or significant at $p=0.05$. The strength of an association was measured as an Odds Ratio (OR), 95\% Confidence Interval (95\% CI). Data analysis was conducted using SAS (version 9.4, SAS Institute Inc.) on IBM cluster.

\section{Results}

We identified a total number of 242,079 new-users of inhaled pharmacotherapies of which $85 \%$ had asthma, $10 \%$ had COPD and 5\% had asthma-COPD overlap. Among them, around $67 \%$ were identified in the first decade (January 1, 1998-December 31, 2007) and around $34 \%$ were identified in the second decade (January 1, 2008-July 31, 2018). The average age of our study population was $52( \pm 22)$ years, $113,712(47 \%)$ were females and 128,367 (53\%) were males. Table 1 summarizes the characteristics of patients with obstructive airway diseases. In relation to other respiratory drugs received before cohort entry, more than 28,000 patients received oral corticosteroids with very few patients receiving methylxanthine $(0.5 \%)$.

Table 2 shows results from the univariate analyses of factors associated with different inhaled pharmacotherapies. Increasing age was significantly associated with increased prescription of all inhaled pharmacotherapies, except ICS and SABA prescriptions. In comparison to females, males were significantly associated with increased prescriptions of ICS/LABA, LABA, LAMA and SAMA, and with decreased prescriptions of ICS, and SABA. In comparison to patients entering cohort between January 1998-December 2007, those entering cohort between January 2008-July 2018 showed significantly higher rates of ICS, LABA and SAMA, and significantly lower rates of ICS/LABA, LAMA, and SABA. Other variables which were significantly associated with the six inhaled pharmacotherapies included body mass index 
Table I Baseline Characteristics Among Patients Diagnosed with Asthma, COPD and Asthma-COPD Overlap

\begin{tabular}{|c|c|c|c|c|}
\hline Characteristics & $\begin{array}{l}\text { Asthma, } \\
N=205,596\end{array}$ & $\begin{array}{l}\text { COPD, } \\
N=24,672\end{array}$ & $\begin{array}{l}\text { Asthma-COPD Overlap, } \\
\mathbf{N}=||, 8||\end{array}$ & $\begin{array}{l}\text { Overall, } \\
N=242,079\end{array}$ \\
\hline Age (mean, STD) & $46.86( \pm 19.6)$ & $79.38( \pm 12.6)$ & $76.08( \pm 15.9)$ & $51.60( \pm 22.0)$ \\
\hline \multicolumn{5}{|l|}{ Gender } \\
\hline Male & $92,849(45.2 \%)$ & $14,350(58.2 \%)$ & $6,513(55.1 \%)$ & $128,367(53 \%)$ \\
\hline Female & I I 2,747 (54.8\%) & $10,322(41.8 \%)$ & $5,298(44.9 \%)$ & $1|3,7| 2(47 \%)$ \\
\hline \multicolumn{5}{|l|}{ Year of cohort entry } \\
\hline January I998-December 2007 & $143,333(69.7 \%)$ & $1 \mathrm{I}, 210(45.4 \%)$ & 6,417 (54.3\%) & $160,960(66.5 \%)$ \\
\hline January 2008-July 2018 & $62,263(30.3 \%)$ & $13,462(54.6 \%)$ & $5,394(45.7 \%)$ & 81,119 (33.5\%) \\
\hline \multicolumn{5}{|l|}{ Body mass index (BMI) } \\
\hline Underweight & $16,84 \mid(11.2 \%)$ & $\mathrm{I}, 25 \mathrm{I}(5.6 \%)$ & 479 (4.4\%) & $|8,57|(\mid 0.2 \%)$ \\
\hline Normal & $59,896(40.0 \%)$ & 8,751 (39.5\%) & $3,885(36.1 \%)$ & $72,532(39.7 \%)$ \\
\hline Overweight & $42,006(28.0 \%)$ & 7,101 (32.0\%) & 3,755 (34.9\%) & $52,862(28.9 \%)$ \\
\hline Obese & $31,086(20.8 \%)$ & 5070 (22.9\%) & $2654(24.6 \%)$ & $38,810(21.2 \%)$ \\
\hline \multicolumn{5}{|l|}{$\mathrm{Rx}$ received as initial treatment } \\
\hline ICS & $71,024(34.6 \%)$ & 3245 (I3.2\%) & $2869(24.3 \%)$ & 77,138 (31.9\%) \\
\hline ICS/LABA & $3737(1.8 \%)$ & 2084 (8.5\%) & 1017 (8.6\%) & $6838(2.8 \%)$ \\
\hline LABA & $1253(0.6 \%)$ & $875(0.4 \%)$ & $410(3.4 \%)$ & $2538(1.1 \%)$ \\
\hline LAMA & $97(0.1 \%)$ & 2436 (9.9\%) & $538(4.7 \%)$ & $3071(1.3 \%)$ \\
\hline SABA & $128,379(62.4 \%)$ & 13,609 (55.2\%) & 6069 (5I.4\%) & $148,057(6 \mid .1 \%)$ \\
\hline SAMA & $1106(0.5 \%)$ & $2423(9.8 \%)$ & $908(7.6 \%)$ & $4437(1.8 \%)$ \\
\hline \multicolumn{5}{|l|}{ Index of deprivation } \\
\hline Least deprived & $46,363(22.6 \%)$ & $3760(15.3 \%)$ & $1873(15.9 \%)$ & $5 \mathrm{I}, 996(21.5 \%)$ \\
\hline Less deprived & $43,752(21.3 \%)$ & $4673(19.0 \%)$ & $2292(19.4 \%)$ & $50,717(21.0 \%)$ \\
\hline Deprived & $42,186(20.5 \%)$ & $4915(16.0 \%)$ & $2320(19.7 \%)$ & $49,421 \quad(20.4 \%)$ \\
\hline More deprived & 38,377 (18.7\%) & $5257(21.3 \%)$ & $2606(22.1 \%)$ & 46,240 (19.1\%) \\
\hline Most deprived & 34,681 (16.9\%) & $6026(24.4 \%)$ & $27 \mid 4(22.9 \%)$ & 43,421 (I8.0\%) \\
\hline \multicolumn{5}{|l|}{ Smoking status } \\
\hline No & $89,199(56.4 \%)$ & $2493(10.4 \%)$ & 2199 (19.1\%) & 93,891 (48.5\%) \\
\hline Yes & 38,991 (24.6\%) & $\mathrm{II}, 2 \mathrm{I} 4$ (46.8\%) & $4220(36.6 \%)$ & $54,425(28.1 \%)$ \\
\hline Ex-smoker & $29,998(19.0 \%)$ & $10,246(42.8 \%)$ & $5112(44.3 \%)$ & $45,356(23.4 \%)$ \\
\hline \multicolumn{5}{|c|}{ Respiratory drugs before cohort entry } \\
\hline \multicolumn{5}{|c|}{ Oral corticosteroid } \\
\hline Yes & $21,803(10.6 \%)$ & $4562(18.5 \%)$ & $2446(20.7 \%)$ & 28,811 (II.9\%) \\
\hline No & I83,793 (89.4\%) & $20,110(81.5 \%)$ & 9365 (79.3\%) & $213,268(88.1 \%)$ \\
\hline \multicolumn{5}{|l|}{ Methylxanthine } \\
\hline Yes & $574(0.3 \%)$ & 331 (1.3\%) & $24 \mathrm{I}(2.0 \%)$ & $1146(0.5 \%)$ \\
\hline No & $205,022(99.7 \%)$ & $24,34 \mathrm{I}(98.7 \%)$ & I I,570 (98.0\%) & $240,933(99.5 \%)$ \\
\hline \multicolumn{5}{|l|}{ Other drugs before cohort entry } \\
\hline \multicolumn{5}{|l|}{ NSAIDs } \\
\hline Yes & $24,211(11.8 \%)$ & $377 \mid(15.3 \%)$ & 1798 (I5.2\%) & $29,780(12.3 \%)$ \\
\hline No & I8I,385 (88.2\%) & $20,90 \mathrm{I}(84.7 \%)$ & $10,013(84.8 \%)$ & $212,299(87.7 \%)$ \\
\hline \multicolumn{5}{|l|}{ Opioids } \\
\hline Yes & $6219(3.0 \%)$ & $2429(9.9 \%)$ & $1025(8.7 \%)$ & $9673(4.0 \%)$ \\
\hline No & 199,377 (97.0\%) & $22,243(90.1 \%)$ & $10,786(91.3 \%)$ & $232,406(96.0 \%)$ \\
\hline \multicolumn{5}{|l|}{ Acetaminophen } \\
\hline Yes & $12,782(6.2 \%)$ & 4245 (I7.2\%) & 1637 (13.9\%) & $18,664(7.7 \%)$ \\
\hline
\end{tabular}

(Continued) 
Table I (Continued).

\begin{tabular}{|c|c|c|c|c|}
\hline Characteristics & $\begin{array}{l}\text { Asthma, } \\
N=205,596\end{array}$ & $\begin{array}{l}\text { COPD, } \\
N=24,672\end{array}$ & $\begin{array}{l}\text { Asthma-COPD Overlap, } \\
\mathbf{N}=||, 8||\end{array}$ & $\begin{array}{l}\text { Overall, } \\
N=242,079\end{array}$ \\
\hline No & $192,8 \mid 4$ (93.8\%) & $20,427(82.8 \%)$ & $10,0174(85.1 \%)$ & $223,415(92.3 \%)$ \\
\hline \multicolumn{5}{|l|}{ Comorbidity in year before cohort entry } \\
\hline 0 & $164,782(80.2 \%)$ & 7771 (3I.5\%) & 4569 (38.7\%) & $177,122(73.2 \%)$ \\
\hline I & $26,980(13.1 \%)$ & 7332 (29.7\%) & 3403 (28.8\%) & $37,715(15.6 \%)$ \\
\hline$>1$ & $13,834(6.7 \%)$ & $9569(38.8 \%)$ & 3839 (32.5\%) & 27,242 (II.2\%) \\
\hline \multicolumn{5}{|l|}{ Physician visits in year before cohort entry } \\
\hline $1-17$ & $184,396(89.7 \%)$ & $16,077(65.2 \%)$ & $8270(70.0 \%)$ & $208,743(86.2 \%)$ \\
\hline $18-35$ & $18,440(9.0 \%)$ & $6,885(27.9 \%)$ & $2896(24.5 \%)$ & $28,221(11.7 \%)$ \\
\hline$>36$ & $2760(1.3 \%)$ & $1710(6.9 \%)$ & $645(5.5 \%)$ & $5115(2.1 \%)$ \\
\hline \multicolumn{5}{|l|}{ No. of hospitalization in year before cohort entry } \\
\hline 0 & 176,156 (85.7\%) & $16,226(65.8 \%)$ & 8643 (73.2\%) & $201,025(83.0 \%)$ \\
\hline I & $20,662(10.1 \%)$ & 5027 (20.4\%) & 1939 (16.4\%) & 27,628 (II.4\%) \\
\hline$>1$ & $8778(4.2 \%)$ & 3419 (13.8\%) & $1229(10.4 \%)$ & 13,426 (5.6\%) \\
\hline
\end{tabular}

Abbreviations: ICS, inhaled corticosteroid; SABA, short-acting beta ${ }_{2}$-agonist; LABA, long-acting beta ${ }_{2}$-agonist; SAMA, short-acting muscarinic antagonist; LAMA, longacting muscarinic antagonist; LAMA, long-acting muscarinic antagonist; COPD, chronic obstructive pulmonary disease; Cl, confidence interval; ACO, asthma-COPD overlap; Rx, prescription; STD, standard deviation; NSAIDs, nonsteroidal anti-inflammatory drugs.

(BMI), index of deprivation, smoking status, other drugs (NSAID, opioids, Acetaminophen), comorbidity, and several disease severity indicators (prescription of methylxanthine, oral corticosteroid and number of hospitalization). However, prescription of ICS/LABA was not significantly associated with Index of deprivation.

Table 3 shows adjusted results from multivariable analysis after controlling for all potential confounders in Table 2. Among the patients diagnosed with asthma, male patients were significantly less likely to be a new-user of ICS monotherapy (adjusted OR 0.97; 95\% CI 0.95-0.99, $p=0.01$ ) and more likely to be prescribed ICS/LABA combination therapy (adjusted OR 1.15; 95\% CI 1.08-1.23, $p<0.0001$ ) than female patients. Among patients with COPD, males were more likely to be prescribed a LABA (adjusted OR 1.29; 95\% CI 1.12-$1.49, p=0.0005$ ), LAMA (adjusted OR 1.21; 95\% CI, 1.101.33, $p<0.0001$ ), and SAMA (adjusted OR 1.11; 95\% CI, $1.01-1.21, p=0.02$ ) and significantly less likely to be prescribed a SABA (adjusted OR 0.84; 95\% CI, 0.80-0.89, $\mathrm{p}<0.0001)$ than female patients. Similar associations were also observed among patients diagnosed with ACO, in which male patients had significantly higher rates in initial prescription of LABA (adjusted OR 1.26; 95\% CI, 1.03-1.55, $p=0.03$ ), LAMA (adjusted OR 1.27; 95\% CI, 1.05-1.53, $p=0.01$ ) and SAMA (adjusted OR 1.28; 95\% CI, 1.11-1.48, $p=0.0008$ ) and significantly lower rate in SABA (adjusted OR $0.89,95 \% \mathrm{CI}$, $0.82-0.96, \mathrm{p}=0.003$ ) than female patients.

\section{Discussion}

Using a large population-based cohort of asthma, COPD and asthma-COPD overlap patients from a period of January 1, 1998 to July 31, 2018, we found significant differences in inhaled pharmacotherapies between females and males among patients with obstructive airway diseases. Adjusted multivariable analyses showed males in comparison to females with COPD or asthma-COPD overlap were more likely to be a new user of a LABA, LAMA, and SAMA and less likely to be a new user of a SABA. Also, males with asthma were more likely to be a newuser of ICS/LABA and less likely to start an ICS.

There are several medications that are currently available for the treatment of asthma but no differential preferences between females and males have been suggested in clinical practice guidelines of asthma and COPD globally. ${ }^{1,2}$ The GINA guideline recommends that all or most asthma patients should have an ICS therapy in their regimen. In COPD however, the treatment option is to avoid ICS if possible as increased use of ICS alone increases the risk of pneumonia in these patients. ${ }^{21,22}$ Noticeably, among patients with asthma, female patients have a significant, albeit small, increase of ICS monotherapy use as initial treatment in comparison with the males in our study. Although the exact reasons for this observed gender differences are not fully understood, the significant increase use of ICS monotherapy among female patients with asthma could be partially explained by more 


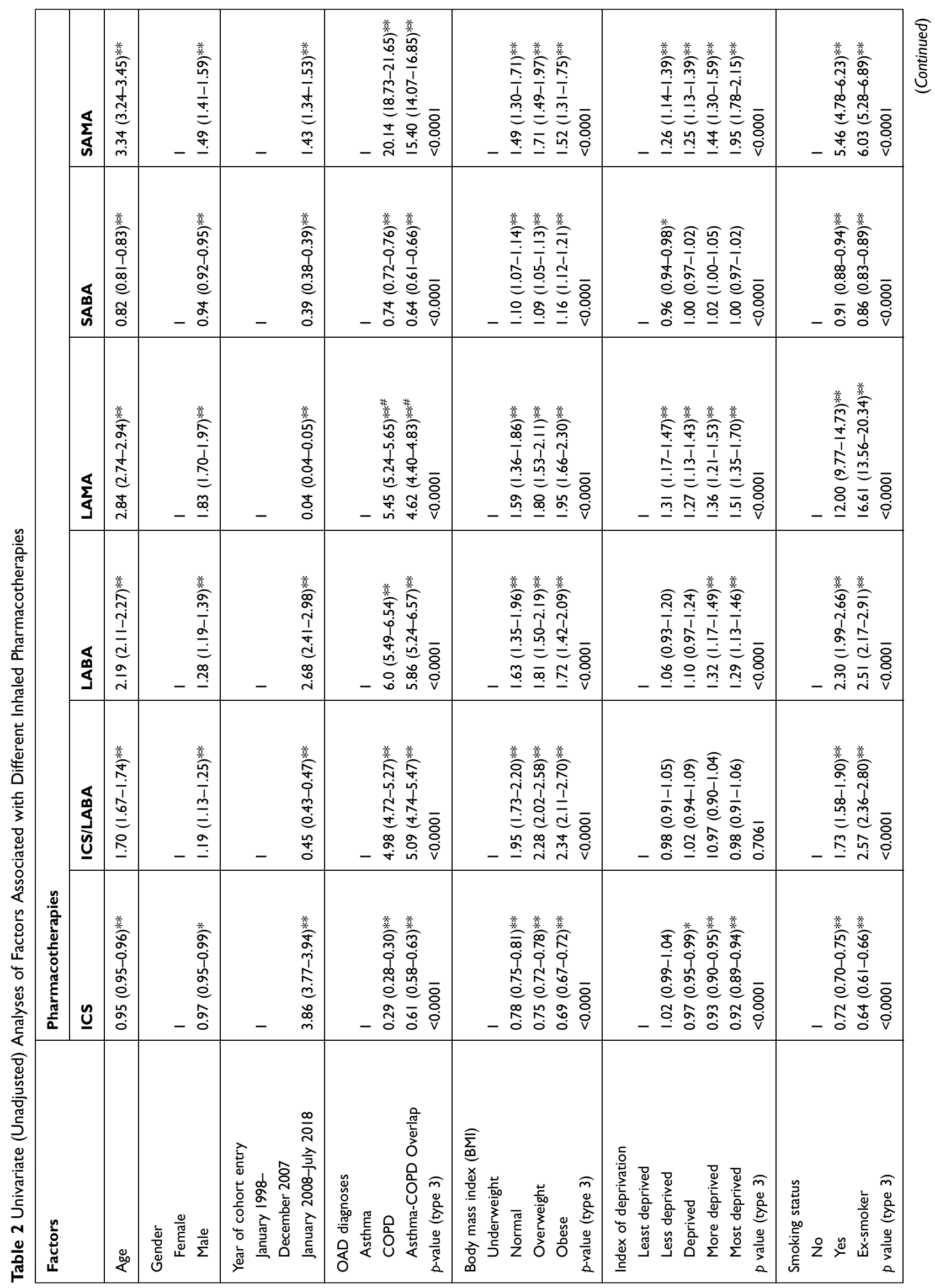




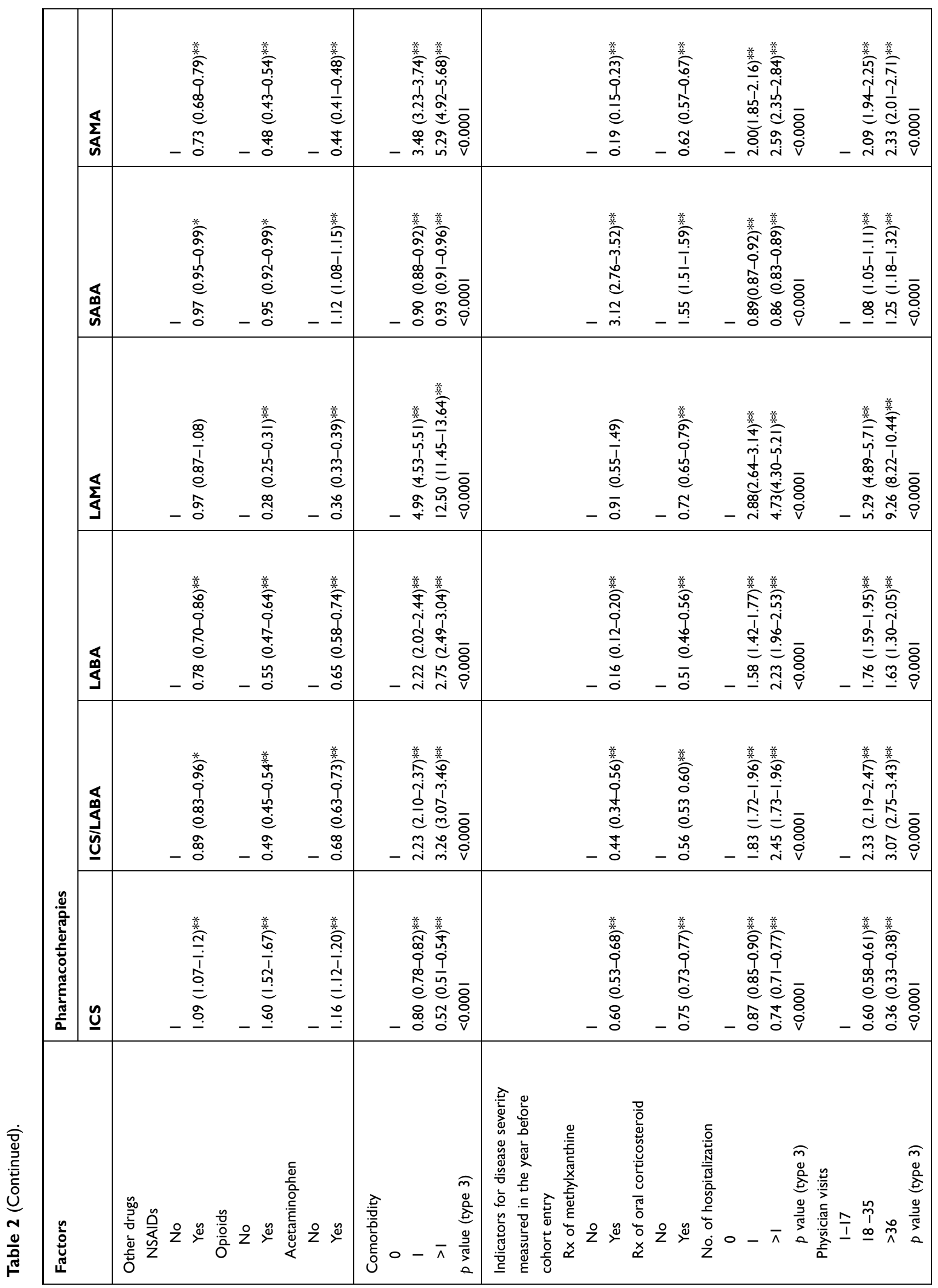




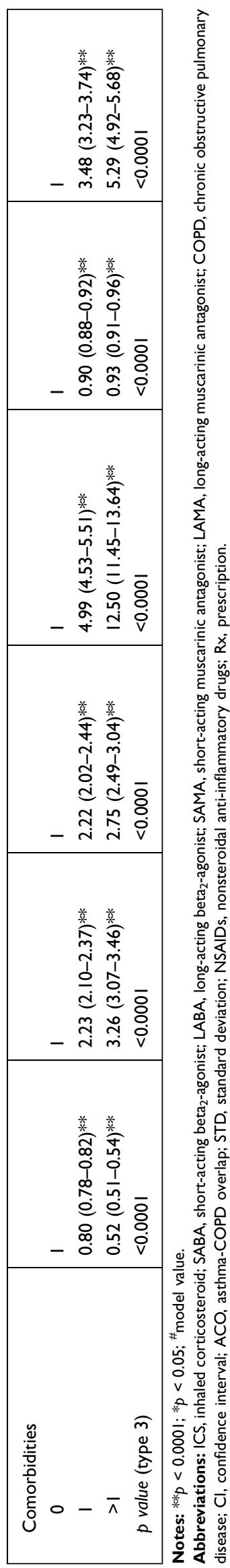

frequent reports of asthma symptoms in female patients than males. In the American Lung Association Asthma Clinical Research Centers (ALA-ACRC) trials to determine if sex differences in asthma control or symptom profiles exist, they observed that females were more likely to report specific symptoms such as nocturnal awakenings, activity limitations, and shortness of breath compared to males. ${ }^{23}$

In contrast to ICS monotherapy initiation, males with asthma received more ICS/LABA as first-line therapy compared to females. It is plausible that male asthmatics were being treated aggressively compared to females as the former were more likely to receive more step-up treatment or superior treatment than the later. It is also interesting that whilst it is known that females have a worse perception of asthma, feel it as more symptomatic and suffer a greater impact on their quality of life (QoL), our findings demonstrated they are less likely to receive ICS/ LABA than their male counterparts initially. ${ }^{24}$ Nevertheless, we found no gender difference in either COPD or asthma-COPD overlap patients prescribed ICS monotherapy, or the combination therapy of ICS/LABA.

The observed gender differences could be partially explained that the average physician recognizes symptoms in males and respond to them more aggressively than they would have done to females with either COPD alone or asthma-COPD overlap. In an observational study to objectively measure and compare reported sleep disturbances due to symptoms in males and females, the authors reported that sleep disturbances were significantly more prevalent in males with COPD compared with controls; whereas there was no significant difference in females. ${ }^{25}$ Indeed, it is perceived that COPD is seen as male-dominated disease. ${ }^{26}$ Alternatively, gender differences may be partially explained by differences in disease characteristics. Papaioannou et al found that female patients were characterized by milder forms of COPD disease relative to males, and comorbidities were more prevalent in males than in females. ${ }^{27}$ As such, it is possible that females presenting with COPD were being treated more with asthma medications. Yet, the COPD GOLD clinical guideline reports no differential treatment between genders. ${ }^{2}$

We observed similar differences among patients with asthma, COPD and asthma-COPD overlap in our study who were new-users of rescue medications. Female patients with either COPD or asthma-COPD overlap were more like to receive SABA compared to males. This is consistent with Dunn et al study which found a trend toward increased use of asthma rescue 
Table 3 Multivariable Analyses of Gender Differences in Inhaled Pharmacotherapies by Three Obstructive Airway Diseases

\begin{tabular}{|c|c|c|c|c|c|c|}
\hline \multirow[t]{2}{*}{ Pharmacotherapies ${ }^{\#}$} & \multicolumn{2}{|l|}{ Asthma } & \multicolumn{2}{|l|}{ COPD } & \multicolumn{2}{|c|}{ Asthma-COPD Overlap } \\
\hline & OR: $95 \% \mathrm{Cl}$ & (aOR: $95 \% \mathrm{Cl}$ ) & OR: $95 \% \mathrm{Cl}$ & aOR: $95 \% \mathrm{CI}$ & OR: $95 \% \mathrm{Cl}$ & aOR: $95 \% \mathrm{Cl}$ \\
\hline \multicolumn{7}{|l|}{ ICS } \\
\hline Female & I & 1 & I & I & I & I \\
\hline Male & $1.03(1.01-1.05)^{*}$ & $0.97(0.95-0.99)^{*}$ & $0.99(0.92-1.07)$ & $0.98(0.90-1.07)$ & $0.89(0.82-0.97)^{*}$ & $0.91(0.83-1.00)$ \\
\hline \multicolumn{7}{|l|}{ ICS/LABA } \\
\hline Female & I & 1 & I & I & 1 & I \\
\hline Male & $0.98(0.92-1.05)$ & $1.15(1.08-1.23)^{* *}$ & $1.07(0.98-1.17)$ & $1.06(0.97-1.18)$ & $1.11(0.97-1.26)$ & $1.09(0.96-1.25)$ \\
\hline \multicolumn{7}{|l|}{ LABA } \\
\hline Female & I & I & I & I & 1 & I \\
\hline Male & $0.94(0.83-1.05)$ & $1.04(0.92-1.18)$ & $1.27(1.10-1.46)^{*}$ & $1.29(1.12-1.49)^{*}$ & $1.23(1.01-1.50)^{*}$ & $1.26(1.03-1.55)^{*}$ \\
\hline \multicolumn{7}{|l|}{ LAMA } \\
\hline Female & 1 & I & I & I & I & I \\
\hline Male & $1.14(0.77-1.70)$ & $1.40(0.93-2.10)$ & $1.20(1 .|I-| .3 \mid)^{* *}$ & $1.21(1.10-1.33)^{* *}$ & $1.33(1.11-1.59)^{*}$ & $1.27(1.05-1.53)^{*}$ \\
\hline \multicolumn{7}{|l|}{ SABA } \\
\hline Female & 1 & 1 & 1 & 1 & I & I \\
\hline Male & $0.97(0.95-0.99)^{*}$ & $1.00(0.98-1.02)$ & $0.87(0.83-0.91) * *$ & $0.84(0.80-0.89)^{* *}$ & $0.93(0.86-0.99)^{*}$ & $0.89(0.82-0.96)^{*}$ \\
\hline \multicolumn{7}{|l|}{ SAMA } \\
\hline Female & 1 & 1 & I & 1 & 1 & 1 \\
\hline Male & $1.12(0.99-1.26)$ & $1.13(0.98-1.30)$ & $1.08(0.99-1.17)$ & $1.11(1.01-1.2 I)^{*}$ & $1.22(1.06-1.40)^{*}$ & $1.28(1.11-1.48)^{*}$ \\
\hline
\end{tabular}

Notes: **p < 0.000I; *p $<0.05$; ${ }^{*}$ Adjusted for all factors listed in Table 2.

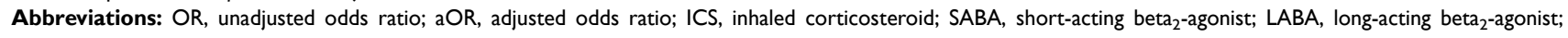
SAMA, short-acting muscarinic antagonist; LAMA, long-acting muscarinic antagonist; COPD, chronic obstructive pulmonary disease; Cl, confidence interval; ACO, asthmaCOPD overlap.

pharmacotherapy in females vs males $(36.2 \%$ vs $13.1 \%$; $p=0.051) .{ }^{28}$ Even though we found that males were less likely to receive rescue medication of SABA, on average, they were on more superior therapy (SAMA) compared to females. This observation may be due to the fact that common respiratory infections in COPD are responsible for most of the incidents of worsened COPD. ${ }^{29}$ Furthermore, males are more susceptible to bacteria and virus infections, infectious complications after surgery, severe sepsis and septic shock. ${ }^{30-33}$

This study has strengths and limitations. A major strength of our study is the size of our study population which consists of more than 240,000 patients. Another strength is the quality of our cohort and its robust capture of medication data. The CPRD is a high-quality database which is representative of approximately 14 million acceptable patients. This attribute makes the study representative of the overall United Kingdom population of obstructive airway patients diagnosed with asthma, COPD and asthma-COPD overlap.

Among limitations is the potential for medication misclassification as the CPRD database does not capture prescriptions from specialists or prescriptions given in a hospital setting. Given most of these agents would be initially prescribed or continued by GPs, the degree of misclassification is likely very low. Another limitation of this study is the lack of information on lung function tests such as $\mathrm{FEV}_{1}$ and $\mathrm{FEV}_{1} / \mathrm{FVC}$ ratio due to large missing values or its unavailability in entirety even though we adjusted for multiple important disease severity indicators such as age, body mass index, material deprivation, smoking status, comorbidities, oral corticosteroid use (indicator for exacerbation), number of hospitalizations, GPs' visits and treatment (comedications). Finally, on the validity of the asthma-COPD overlap subgroup. Just as the clinical definition of asthma or COPD is still debatable, as things stand, there is not a standard definition for patients with asthma-COPD overlap. However, we defined these patients as having; 1) COPD read code and 2) asthma read code and 3) an ex or current smoker (if never smoked, exposure to wood smoke, biofuels, randon gas or second-hand smoke) before the index date. The read codes for both asthma and COPD in the CPRD have been extensively validated and used in several studies. 


\section{Conclusion}

Albeit in a more specific population, our findings are consistent with van der Verde et al whom found that overall prescription rates were substantially higher in females than in males with diverse regional and ethnic differences and called for renewed efforts to close expanding gender treatment gap. ${ }^{34}$ Our findings are novel and highlights GPs potential unconscious bias in management of obstructive airway disease patients. In conclusion, we observed an overall gender difference in first time drug use to treat patients with asthma, COPD or asthma-COPD overlap who are new-users of inhaled pharmacotherapies from January-01, 1998 to July-31, 2018. Adjusting for proxies of disease severity, smoking and socioeconomic (material deprivation) status did not change the association by gender.

\section{Abbreviations}

OAD, obstructive airway disease; ICS, inhaled corticosteroid; SABA, short-acting beta ${ }_{2}$-agonist; LABA, long-

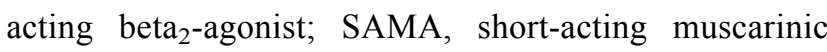
antagonist; LAMA, long-acting muscarinic antagonist; LAMA, long-acting muscarinic antagonist; COPD, chronic obstructive pulmonary disease; CI, confidence interval; ACO, asthma-COPD overlap; Rx, prescription; STD, standard deviation; NSAIDs, nonsteroidal antiinflammatory drugs; CPRD, Clinical Practice Research Datalink.

\section{Disclaimer}

The study funder was not involved in the study design or the writing of the protocol.

\section{Acknowledgments}

This study is based in part on data from the Clinical Practice Research Datalink (CPRD-GOLD) obtained under licence from the UK Medicines and Healthcare products Regulatory Agency. However, the interpretation and conclusions contained in this study are those of the authors alone.

\section{Author Contributions}

All authors made a significant contribution to the work reported, whether that is in the conception, study design, execution, acquisition of data, analysis and interpretation, or in all these areas; took part in drafting, revising or critically reviewing the article; gave final approval of the version to be published; have agreed on the journal to which the article has been submitted; and agree to be accountable for all aspects of the work.

\section{Funding}

This work was supported by a research grant from Canada Research Respiratory Network (CRRN), Ottawa, Canada (Young Investigator Award, 2017).

\section{Disclosure}

The authors report no conflicts of interest for this work.

\section{References}

1. GINA. Global initiative for asthma, June 2019 update. Available from: https://ginasthma.org/wp-content/uploads/2019/06/GINA2019-main-report-June-2019-wms.pdf. Accessed December 24, 2019.

2. GOLD. COPD gold guidelines 2019. 2019. Available from: https:// goldcopd.org/wp-content/uploads/2018/11/GOLD-2019-v1. 7-FINAL-14Nov2018-WMS.pdf. Accessed December 24, 2019.

3. ACOS. Asthma-COPD overlap syndrome. Available from: https:// goldcopd.org/wp-content/uploads/2016/04/GOLD_ACOS_2015.pdf. Accessed January 24, 2019.

4. Cadeddu $\mathrm{C}$, et al. Literature review of gender differences in respiratory conditions: a focus on asthma and Chronic Obstructive Pulmonary Disease (COPD). Ig Sanita Pubbl. 2016;72(5):481-504.

5. Geller JC, Cassens S, Brosz M, et al. Achievement of guideline-defined treatment goals in primary care: the German Coronary Risk Management (CoRiMa) study. Eur Heart J. 2007;28 (24):p. 3051-8. doi:10.1093/eurheartj/ehm520

6. Journath G, Hellénius M-L, Petersson U, et al. Sex differences in risk factor control of treated hypertensives: a national primary healthcare-based study in Sweden. Eur J Cardiovasc Prev Rehabil. 2008;15(3):258-262. doi:10.1097/HJR.0b013e3282f37a45

7. Gouni-Berthold I, Berthold HK. Role of physician gender in drug therapy. Handb Exp Pharmacol. 2012;214:183-208.

8. Bushnell C, McCullough LD, Awad IA, et al. Guidelines for the prevention of stroke in women: a statement for healthcare professionals from the American Heart Association/American Stroke Association. Stroke. 2014;45(5):1545-1588. doi:10.1161/01. str.0000442009.06663.48

9. Maas AH, van der Schouw YT, Regitz-Zagrosek V, et al. Red alert for women's heart: the urgent need for more research and knowledge on cardiovascular disease in women: proceedings of the workshop held in Brussels on gender differences in cardiovascular disease, 29 September 2010. Eur Heart J. 2011;32(11):1362-1368. doi:10.1093/eurheartj/ehr048

10. Pignataro FS, Bonini M, Forgione A, et al. Asthma and gender: the female lung. Pharmacol Res. 2017;119(p):384-390. doi:10.1016/j. phrs.2017.02.017

11. Asthma GIF, Global strategy for asthma management and prevention. Global Initiative for Asthma; 2018. Available from: www. ginasthma. org.

12. Amegadzie JE, Gorgui J, Acheampong L. et al. Comparative safety and effectiveness of inhaled bronchodilators and corticosteroids for treating asthma-COPD overlap: a systematic review and meta-analysis. J Asthma;2019. 1-16. doi:10.1080/02770903.20 19.1687716

13. Yang Y, Carlin AS, Faustino PJ, et al. Participation of women in clinical trials for new drugs approved by the food and drug administration in 2000-2002. J Womens Health (Larchmt). 2009;18 (3):303-310. doi:10.1089/jwh.2008.0971 
14. Liu KA, Mager NA. Women's involvement in clinical trials: historical perspective and future implications. Pharm Pract (Granada). 2016;14(1):708. doi:10.18549/PharmPract.2016.01.708

15. Ayanian JZ, Epstein AM. Differences in the use of procedures between women and men hospitalized for coronary heart disease. $N$ Engl J Med. 1991;325(4):221-225. doi:10.1056/NEJM19910725 3250401

16. Steingart RM, Packer M, Hamm P, et al. Sex differences in the management of coronary artery disease. Survival and Ventricular Enlargement Investigators. $N$ Engl J Med. 1991;325(4):226-230. doi:10.1056/NEJM199107253250402

17. Herrett E, Gallagher AM, Bhaskaran K, et al. Data resource profile: clinical practice research datalink (CPRD). Int J Epidemiol. 2015;44 (3):827-836. doi:10.1093/ije/dyv098

18. McDonald L, Schultze A, Carroll R, et al. Performing studies using the UK clinical practice research datalink: to link or not to link? Eur J Epidemiol. 2018;33(6):601-605. doi:10.1007/s10654-018-0389-5

19. Quint JK, Mullerova H, DiSantostefano RL, et al. Validation of chronic obstructive pulmonary disease recording in the clinical practice research datalink (CPRD-GOLD). BMJ Open. 2014;4(7): e005540. doi:10.1136/bmjopen-2014-005540

20. Nissen F, Morales DR, Mullerova H, et al. Validation of asthma recording in the clinical practice research datalink (CPRD). BMJ Open. 2017;7(8):e017474. doi:10.1136/bmjopen-2017-017474

21. Suissa S, Patenaude V, Lapi F, et al. Inhaled corticosteroids in COPD and the risk of serious pneumonia. Thorax. 2013;68(11):1029-1036. doi:10.1136/thoraxjnl-2012-202872

22. Morjaria JB, Rigby A, Morice AH. Inhaled corticosteroid use and the risk of pneumonia and COPD exacerbations in the UPLIFT study. Lung. 2017;195(3):281-288. doi:10.1007/s00408-017-9990-8

23. McCallister JW, Holbrook JT, Wei CY, et al. Sex differences in asthma symptom profiles and control in the American Lung Association Asthma Clinical Research Centers. Respir Med. 2013;107(10):1491-1500. doi:10.1016/j.rmed.2013.07.024

24. Colombo D, Zagni E, Ferri F, et al. Gender differences in asthma perception and its impact on quality of life: a post hoc analysis of the PROXIMA (Patient Reported Outcomes and Xolair $\left({ }^{\circledR}\right)$ In the Management of Asthma) study. Allergy Asthma Clin Immunol. 2019;15(p):65. doi:10.1186/s13223-019-0380-z
25. Theorell-Haglow J, Ólafsdóttir IS, Benediktsdóttir B, et al. Sex differences in reported and objectively measured sleep in COPD. Int J Chron Obstruct Pulmon Dis. 2016;11(p):151-160. doi:10.2 147/COPD.S94268

26. Tsiligianni I, Rodríguez MR, Lisspers $\mathrm{K}$, et al. Call to action: improving primary care for women with COPD. NPJ Prim Care Respir Med. 2017;27(1):11. doi:10.1038/s41533-017-0013-2

27. Papaioannou AI, Bania E, Alexopoulos E, et al. Sex discrepancies in COPD patients and burden of the disease in females: a nationwide study in Greece (Greek Obstructive Lung Disease Epidemiology and health ecoNomics: GOLDEN study). Int J Chron Obstruct Pulmon Dis. 2014;9(p):203-213. doi:10.2147/COPD.S52500

28. Dunn RM, Lehman E, Chinchilli VM, et al. Impact of age and sex on response to asthma therapy. Am J Respir Crit Care Med. 2015;192 (5):551-558. doi:10.1164/rccm.201503-0426OC

29. Sethi S, Murphy TF. Infection in the pathogenesis and course of chronic obstructive pulmonary disease. $N$ Engl J Med. 2008;359 (22):2355-2365. doi:10.1056/NEJMra0800353

30. Offner PJ, Moore EE, Biffl WL. Male gender is a risk factor for major infections after surgery. Arch Surg. 1999;134(9):935-8; discussion 938-40. doi:10.1001/archsurg.134.9.935

31. Traub S, Demaria O, Chasson L, et al. Sex bias in susceptibility to MCMV infection: implication of TLR9. PLoS One. 2012;7(9): e45171. doi:10.1371/journal.pone.0045171

32. Wichmann MW, Inthorn D, Andress HJ, et al. Incidence and mortality of severe sepsis in surgical intensive care patients: the influence of patient gender on disease process and outcome. Intensive Care Med. 2000;26(2):167-172. doi:10.1007/s001340050041

33. Yamamoto Y, Saito H, Setogawa T, et al. Sex differences in host resistance to Mycobacterium marinum infection in mice. Infect Immun. 1991;59(11):4089-4096. doi:10.1128/IAI.59.11.40894096.1991

34. van der Velde RY, Wyers CE, Teesselink E, et al. Trends in oral anti-osteoporosis drug prescription in the United Kingdom between 1990 and 2012: variation by age, sex, geographic location and ethnicity. Bone. 2017;94(p):50-55. doi:10.1016/j.bone.2016.10.013

International Journal of Chronic Obstructive Pulmonary Disease

\section{Publish your work in this journal}

The International Journal of COPD is an international, peer-reviewed journal of therapeutics and pharmacology focusing on concise rapid reporting of clinical studies and reviews in COPD. Special focus is given to the pathophysiological processes underlying the disease, intervention programs, patient focused education, and self management protocols. This journal is indexed on PubMed Central, MedLine and CAS. The manuscript management system is completely online and includes a very quick and fair peer-review system, which is all easy to use. Visit http://www.dovepress.com/testimonials.php to read real quotes from published authors.

Submit your manuscript here: https://www.dovepress.com/international-journal-of-chronic-obstructive-pulmonary-disease-journal 